\section{Renata Jardim'}

Sandhi Maria Barreto"

Luana Giatti"

Programa de Pós-Graduação em Saúde Pública. Faculdade de Medicina (FM). Universidade Federal de Minas Gerais (UFMG). Belo Horizonte, MG, Brasil

Departamento de Medicina Preventiva e Social. FM-UFMG. Belo Horizonte, MG, Brasil

\section{Correspondence:}

Renata Jardim

Av. Alfredo Balena, 190, $8^{\circ}$ andar

Santa Efigênia

30190-100 Belo Horizonte, MG, Brasil

E-mail: renatajardim.m@gmail.com

\section{Self-reporting and secondary informant reporting in health assessments among elderly people}

\begin{abstract}
OBJECTIVE: To analyze whether the explanatory model for health assessments among elderly people based on self-reporting is comparable with the model based on secondary informant reporting, and whether the secondary informant's selfassessed health influences the health assessment among these elderly people.

METHODS: This was a cross-sectional study on 230 pairs consisting of one elderly individual and one secondary informant, conducted in Belo Horizonte, Southeastern Brazil, in 2007. The sociodemographic and health variables of the elderly people were investigated by means of a structured interview. Multiple logistic regression was used to analyze associations with self-assessed poor health among the elderly individuals and with the information provided by the secondary informants.
\end{abstract}

RESULTS: In the model based on self-reporting, the variable most strongly associated with poor health assessment among these elderly individuals was the presence of limitations or disabilities relating to performing activities of daily living and/or mobility. In the model based on the secondary informant, the most important explanatory variable was the number of chronic diseases presented by the elderly individual. Furthermore, the chance that the secondary informant would assess the elderly individual's health as poor was three times greater when this informant assessed his own health as poor.

CONCLUSIONS: The results showed significant differences between the health assessment model for elderly people based on the individual's own responses and the model based on a secondary informant's responses. The elderly individuals tended to place value on their limitations or disabilities relating to performing activities of daily living and mobility, while secondary informants tended to place value on the diagnoses of chronic diseases. Secondary informants with poor self-assessed health presented almost three times greater chance of reporting elderly individuals' health as the same as their own. Thus, self-reported information better reflects individuals' health conditions than do reports from secondary informants.

DESCRIPTORS: Health of the Elderly. Health Evaluation. Self Assessment (Psychology). Observer Variation. Health Knowledge, Attitudes and Practice. Bias (Epidemiology). Cross-Sectional Studies.

\section{INTRODUCTION}

Self-assessment of health as poor predicts events such as hospitalization, mortality and functional decline among the elderly. ${ }^{6,18}$ It expresses a multidimensional comprehension of the state of health and includes objective factors 
like the health condition, ${ }^{7}$ and subjective factors like the capacity to deal with problems. ${ }^{16}$

Because self-assessment is useful and easy to obtain, it has been increasingly used as a health indicator in epidemiological studies. ${ }^{7,8,11}$ Nonetheless, although such assessments reflect an appreciation of personal and subjective nature, some health surveys have obtained assessments from informants other than the subject under investigation. ${ }^{8}$ The main justification for using secondary informants in household surveys is the difficulty in encountering all the people living in the household at the time of the interview. ${ }^{10,12}$ This was the case with the National Household Sampling Survey (PNAD) in Brazil. The PNAD data from 1998, in the metropolitan regions, show that $54 \%$ of the individuals aged 15 to 44 years were assessed regarding general state of health by secondary informants. ${ }^{3}$ The same was found in $64 \%$ of the interviews with individuals aged over 17 years in the PNAD of 2003.

The predictive power of general health assessments made by secondary informants is unknown. Likewise, bias in cross-sectional studies with data gathering based on secondary informants cannot be ignored. ${ }^{3,17}$ The attempts to control for potential bias resulting from using secondary informants have included introduction of the variable "answered by secondary informant" in multiple analyses, ${ }^{1,3}$ or stratification of the analysis and comparison of the magnitude and direction of the association when the information comes from the study subjects themselves and when it is obtained from secondary informants. ${ }^{8,14}$ However, these strategies do not ensure adequate assessment of the errors introduced through using secondary informants, since the individuals with lower availability for participating in such studies tend to differ from those who are more frequently encountered at home. Thus, the assumption that explanatory models based on analysis on responses obtained from secondary informants are similar to those based on responses from the study subjects themselves cannot be guaranteed.

In a previous study, there was poor agreement between elderly individuals' self-assessments of their health and assessments made by secondary informants. ${ }^{19}$ For this reason, the impact from using secondary informants for assessing elderly individuals' health needs to be investigated, given that the percentage of responses obtained from secondary informants is high in studies based on the supplementary healthcare data in PNAD. ${ }^{20}$

The present study aimed to analyze whether the explanatory model for assessing elderly individuals' health based on self-reporting is comparable with the model using reporting by secondary informants, and to test whether secondary informants' assessments of their own health influence the way in which they rate elderly subjects' health.

\section{METHODS}

A cross-sectional epidemiological study was conducted among elderly individuals living in a low-income urban area in Belo Horizonte, Southeastern Brazil. This study formed part of the Aging and Health project, which was a population-based survey investigating the health profile of elderly people living within the coverage area of the Vila Pinho Healthcare Center, in Belo Horizonte.

The sample was based on registrations by the healthcare center in 2006 and updates by community health agents. The elderly people were selected by means of randomized sampling, stratified by sex and age. The sample size calculation for testing the agreement between elderly individuals and secondary informants included in this study $(\mathrm{n}=230)$, was based on a minimum kappa coefficient of 0.6 , precision of 0.10 and confidence level of $95 \%$, for an estimated prevalence of self-assessed poor health of $50 \%$.

Through a draw, 405 elderly people were selected, i.e. $92 \%$ of the participants in the Aging and Health project. Of these, $230(62 \%)$ had two or more people aged 18 years or more living with them and constituted the study population in the present work.

Data gathering took place between April and October 2007 , by means of interviews that were held at the healthcare center or at the interviewees' homes or workplaces. These were arranged in advance by the community health agents.

Trained professionals conducted structured interviews, and reliability determinations were made on $7 \%$ of the participants by means of reapplying questions from the general questionnaire of the Aging and Health project. This produced a mean kappa value of 0.79 .

The elderly individuals answered questions on their health, and the term "secondary informant" was used to indicate people living with the study subject who supplied information about the elderly subject's health and their own health. To avoid loss of information, the secondary informants were instructed to choose the response option that they considered most appropriate from their own perspective.

All the interviews with elderly subjects and secondary informants were conducted separately, in order to avoid any contamination of information. ${ }^{5}$ Regarding the time interval between these interviews, $67 \%$ of them were held on the same day and $91 \%$ within seven days.

The structured questionnaire contained 50 questions that were similar to or the same as those used in PNAD 2003, along with questions on lifestyle, health conditions and use of health services. 
Two explanatory models were tested. In the first model, the dependent variable was poor or very poor health, self-assessed by the elderly individual. This was measured through the question "In a general manner, do you consider that your health is: very good, good, fair, poor or very poor?" In the second model, the dependent variable was an assessment that the elderly individual's health was poor or very poor, based on the secondary informant's answer to the following question: "In a general manner, do you consider that the health of Mr./ Ms. NAME OF ELDERLY INDIVIDUAL is very good, good, fair, poor or very poor?". The responses were gathered into two groups: "very good, good and fair" and "poor and very poor", which were categorized as "good" and "poor", respectively.

The influence of the secondary informants' responses perspective ${ }^{9}$ on the explanatory model based on their responses was investigated by testing the dependent variable based on the elderly individuals' perspective. This perspective was obtained from the question: "In a general manner, does Mr./Ms. [NAME OF ELDERLY INDIVIDUAL] consider that his state of health is very good, good, fair, poor or very poor?".

In the model based on the health assessments obtained from secondary informants, all the independent variables used were also reported by the secondary informants, thereby repeating the procedure used in PNAD and in other studies that used secondary informants.

The explanatory variables tested were grouped as follows: socioeconomic and demographic characteristics; lifestyle; health conditions; and use of health services.

To analyze the association between health assessed as poor and functional capacity, the variable "presence of great difficulty or incapacity in performing at least one of the six activities of daily living (ADLs)/mobility investigated" was constructed. The activities analyzed were: feeding oneself; having a bath/shower or going to the bathroom; running, lifting heavy objects, practicing sports or doing heavy work; pushing a table or doing domestic repairs; stooping, kneeling down or bending over; walking for more than one kilometer and walking around 100 meters. Each activity had four response options: unable to do it; great difficulty in doing it; slight difficulty in doing it; and no difficulty in doing it. All the respondents who said that they had "great difficulty" or were "unable" to do at least one activity were grouped in the category that was positive for great difficulty/incapacity relating to ADLs/mobility.

After descriptive analysis on the variables investigated, the factors associated with self-assessed poor health among the elderly individuals were then analyzed. This analysis was performed in three stages, using logistic regression. The magnitude of the association was measured by means of the odds ratio (OR), and the statistical significance was determined using the $95 \%$ confidence interval $(95 \% \mathrm{CI})$.

In the first stage, bivariate analysis was performed, taking into consideration all the explanatory variables in each group. All the variables showing an association with the dependent variable at the level of $p<0.20$ were then tested in intermediate models, taking into consideration only the variables belonging to the same group. In the third stage, the variables that remained statistically associated with the dependent variables at the level of $\mathrm{p}<0.05$ were kept in the final model.

Next, the analysis on the factors associated with assessments of the elderly individuals' health as poor was repeated, using the assessments made by the secondary informants. Finally, the secondary informant' assessments of their own health were added to the secondary informant model, with the aim of testing the modifying effect of how the secondary informants assessed the elderly individuals' health.

The fit of the final models for assessments of the elderly subjects' health as poor was verified using the HosmerLemeshow test.

The EpiData 3.11 software was used for data entry and the Stata software, version 9.0, was used for the statistical analysis.

The research project was approved by the Research Ethics Committee of the Universidade Federal de Minas Gerais in October 2006 (Report No. 379/2006) and by the Research Ethics Committee of the Municipal Health Department of Belo Horizonte in January 2007 (Report No. 065/2007). All the participants signed a free and informed consent statement.

\section{RESULTS}

Out of the 230 elderly individuals, $58 \%$ were women, $40 \%$ were married and $34 \%$ had been widowed. Their mean and median ages were 70 and 67 years, respectively. Regarding color/race, $68 \%$ of the elderly individuals classified themselves as mixed race and $27 \%$ as white. Most of them said that their mean family income was not more than two Brazilian minimum wages per month $(62 \%)$. The mean and median schooling levels were both three years, and $44 \%$ of the elderly individuals said that they did not know how to read or write; $30 \%$ of the elderly individuals had been working during the week preceding the interview.

With regard to lifestyle, $22 \%$ of the elderly individuals said that they were current smokers and $25 \%$ undertook leisure-time physical activity at least three times a week. Among the morbidities reported, 73\% reported that they had been given a medical diagnosis of arterial 
Table 1. Result from bivariate analysis on factors associated with assessment of the elderly subjects' health as poor, according to sociodemographic and lifestyle variables: analyses based on self-assessment and on information supplied by secondary informants. Belo Horizonte, Southeastern Brazil, 2007.

\begin{tabular}{|c|c|c|c|c|c|c|c|c|c|c|c|c|}
\hline \multirow{3}{*}{ Variable } & \multicolumn{6}{|c|}{ Self-assessed health } & \multicolumn{6}{|c|}{$\begin{array}{l}\text { Assessment of elderly subjects' health made } \\
\text { by secondary informants }\end{array}$} \\
\hline & \multicolumn{2}{|c|}{ Good } & \multicolumn{2}{|c|}{ Poor } & \multirow{2}{*}{ OR $(95 \% \mathrm{Cl})$} & \multirow{2}{*}{$\mathrm{p}$} & \multicolumn{2}{|c|}{ Good } & \multicolumn{2}{|c|}{ Poor } & \multirow{2}{*}{ OR $(95 \% \mathrm{Cl})$} & \multirow{2}{*}{$\mathrm{p}$} \\
\hline & $n$ & $\%$ & $\mathrm{n}$ & $\%$ & & & $\mathrm{n}$ & $\%$ & $\mathrm{n}$ & $\%$ & & \\
\hline \multicolumn{13}{|l|}{ Sociodemographic } \\
\hline \multicolumn{13}{|l|}{ Sex } \\
\hline Male & 85 & 43 & 14 & 45 & 1 & & 78 & 42 & 21 & 46 & 1 & \\
\hline Female & 114 & 57 & 17 & 55 & $0.91(0.42 ; 1.94)$ & 0.798 & 106 & 58 & 25 & 54 & $0.88(0.46 ; 1.68)$ & 0.690 \\
\hline \multicolumn{13}{|l|}{ Age (years) } \\
\hline 60 to 64 & 77 & 39 & 06 & 19 & 1 & & 71 & 39 & 12 & 26 & 1 & \\
\hline 65 to 69 & 43 & 21 & 13 & 42 & $3.88(1.38 ; 10.94)$ & 0.010 & 43 & 23 & 13 & 28 & $1.79(0.75 ; 4.27)$ & 0.191 \\
\hline$\geq 70$ & 79 & 40 & 12 & 39 & $1.95(0.70 ; 5.45)$ & 0.204 & 70 & 38 & 21 & 46 & $1.78(0.81 ; 3.88)$ & 0.151 \\
\hline \multicolumn{13}{|l|}{ Marital status } \\
\hline $\begin{array}{l}\text { Married/stable } \\
\text { partnership }\end{array}$ & 82 & 41 & 15 & 48 & 1 & & 74 & 40 & 18 & 39 & 1 & \\
\hline Single/divorced & 50 & 25 & 05 & 16 & $0.55(0.19 ; 1.60)$ & 0.269 & 39 & 21 & 07 & 15 & $0.74(0.28 ; 1.92)$ & 0.533 \\
\hline Widowed & 67 & 34 & 11 & 35 & $0.90(0.39 ; 2.08)$ & 0.801 & 71 & 39 & 21 & 46 & $1.22(0.60 ; 2.47)$ & 0.589 \\
\hline \multicolumn{13}{|l|}{ Color } \\
\hline White & 56 & 28 & 07 & 23 & 1 & & 67 & 36 & 14 & 35 & 1 & \\
\hline Black/mixed & 133 & 67 & 23 & 74 & $1.38(0.56 ; 3.41)$ & 0.481 & 113 & 61 & 29 & 63 & $1.23(0.61 ; 2.49)$ & 0.568 \\
\hline Oriental/indigenous & 10 & 05 & 01 & 03 & $0.80(0.10 ; 7.22)$ & 0.842 & 04 & 02 & 03 & 07 & $3.59(0.72 ; 17.84)$ & 0.118 \\
\hline \multicolumn{13}{|c|}{ Monthly family income (minimum salaries) } \\
\hline Up to 1 & 99 & 50 & 18 & 58 & 1 & & 47 & 25 & 17 & 37 & 1 & \\
\hline 1 to 3 & 49 & 24 & 08 & 26 & $0.90(0.36 ; 2.21)$ & 0.815 & 86 & 47 & 20 & 44 & $0.64(0.31 ; 1.34)$ & 0.241 \\
\hline$\geq 3.1$ & 51 & 26 & 05 & 16 & $0.54(0.19 ; 1.54)$ & 0.248 & 51 & 28 & 09 & 20 & $0.49(0.20 ; 1.20)$ & 0.118 \\
\hline \multicolumn{13}{|l|}{ Schooling (years of study) } \\
\hline 0 to 3 & 113 & 58 & 20 & 69 & 1 & & 104 & 58 & 29 & 63 & 1 & \\
\hline 4 to 7 & 73 & 37 & 08 & 28 & $0.62(0.26 ; 1.48)$ & 0.281 & 66 & 37 & 15 & 33 & $0.82(0.41 ; 1.63)$ & 0.564 \\
\hline 8 to 20 & 10 & 05 & 01 & 03 & $0.57(0.10 ; 4.66)$ & 0.596 & 09 & 05 & 02 & 04 & $0.80(0.16 ; 3.89)$ & 0.779 \\
\hline \multicolumn{13}{|c|}{ Working during the preceding week } \\
\hline Yes & 67 & 34 & 04 & 13 & 1 & & 63 & 34 & 09 & 20 & 1 & \\
\hline No & 132 & 66 & 27 & 87 & $3.43(1.15 ; 10.19)$ & 0.027 & 121 & 66 & 37 & 80 & $2.14(0.97 ; 4.71)$ & 0.059 \\
\hline \multicolumn{13}{|l|}{ Lifestyle } \\
\hline \multicolumn{13}{|l|}{ Current smoker } \\
\hline No & 21 & 23 & 03 & 23 & 1 & & 23 & 27 & 08 & 33 & 1 & \\
\hline Yes & 72 & 77 & 10 & 77 & $0.97(0.24 ; 3.86)$ & 0.968 & 61 & 73 & 16 & 67 & $0.75(0.28 ; 2.00)$ & 0.570 \\
\hline Alcohol consumption & st $30 c$ & lays) & & & & & & & & & & \\
\hline No & 165 & 83 & 30 & 97 & 1 & & 154 & 84 & 39 & 85 & 1 & \\
\hline Yes & 34 & 17 & 01 & 03 & $0.17(0.21 ; 1.23)$ & 0.078 & 30 & 16 & 07 & 15 & $0.92(0.38 ; 2.25)$ & 0.858 \\
\hline Physical activity during & eisure & time & & & & & & & & & & \\
\hline Yes & 52 & 26 & 04 & 13 & 1 & & 42 & 23 & 04 & 09 & 1 & \\
\hline No & 147 & 74 & 27 & 87 & $2.39(0.80 ; 7.15)$ & 0.120 & 141 & 77 & 42 & 91 & $3.13(1.06 ; 9.23)$ & 0.039 \\
\hline Consumption of fresh fr & it and & raw & salad & (last & seven days) & & & & & & & \\
\hline Yes & 64 & 32 & 13 & 42 & 1 & & 40 & 22 & 17 & 37 & 1 & \\
\hline No & 135 & 68 & 18 & 58 & $0.66(0.30 ; 1.42)$ & 0.286 & 144 & 78 & 29 & 63 & $0.47(0.24 ; 0.95)$ & 0.035 \\
\hline
\end{tabular}


hypertension. Most of the elderly individuals (85\%) had some degree of limitation on activities, and $60 \%$ had great difficulty or incapacity in relation to at least one of the activities investigated.

Most of the secondary informants were women (73\%), with ages ranging from 19 to 78 years, and $88 \%$ were under 60 years of age. The mean and median ages were both 43 years; $71 \%$ considered themselves to be black or of mixed race, while $28 \%$ classified themselves as white. The mean and median schooling levels of the secondary informants were both seven years. With regard to the elderly individuals' own health, $31 \%$ of them assessed it as very good or good, $54 \%$ as fair and $15 \%$ as poor or very poor. According to the secondary informants, from their own perspective, the elderly individuals' health was very good or good in $33 \%$ of the cases, fair in $47 \%$ and poor or very poor in $20 \%$. When the secondary informants were called on to respond according to the elderly individuals' perspective, these figures were $40 \%, 36 \%$ and $24 \%$, respectively.

The results from the bivariate analyses on associations with assessments of the elderly subjects' health as poor from the elderly individuals' and the secondary informants' perspectives are shown in Tables 1 and 2 , respectively. Age and work situation in the week preceding the interview were associated when the health assessment was made by the elderly individuals themselves. Physical activity at least three times a week was significant only for the assessment of elderly health as poor made by secondary informants. The same was found for the variable "hospitalization during the last 12 months". The variables in the health condition group were positively associated with assessment of the elderly health as poor, independent of the respondent. In the multiple analysis per group of variables, differences in the variables associated with poor health among the

Table 2. Result from bivariate analysis on factors associated with assessment of the elderly subjects' health as poor, according to health indicators and use of health services: analyses based on self-assessment and on information supplied by secondary informants. Belo Horizonte, Southeastern Brazil, 2007.

\begin{tabular}{|c|c|c|c|c|c|c|c|c|c|}
\hline \multirow{3}{*}{ Variable } & \multicolumn{4}{|c|}{ Self-assessed health } & \multicolumn{5}{|c|}{$\begin{array}{l}\text { Assessment of elderly subjects' health made by } \\
\text { secondary informants }\end{array}$} \\
\hline & Good & Poor & $\cap P(O 50 / C)$ & & & & Poor & (1) & \\
\hline & $\mathrm{n} \quad \%$ & $\mathrm{n} \quad \%$ & (3) & $p$ & $\mathrm{n}$ & $\%$ & $\mathrm{n} \quad \%$ & (3) $(9300(1)$ & $p$ \\
\hline
\end{tabular}

Health conditions

Number of chronic diseases ${ }^{\mathbf{a}}$

\begin{tabular}{|c|c|c|c|c|c|c|c|c|c|c|c|c|}
\hline Up to 1 & 75 & 38 & 09 & 29 & 1 & & 79 & 43 & 07 & 15 & 1 & \\
\hline 2 to 3 & 81 & 41 & 08 & 26 & $0.82(0.30 ; 2.24)$ & 0.703 & 76 & 41 & 21 & 46 & $3.12(1.25 ; 7.76)$ & 0.014 \\
\hline$\geq 4$ & 43 & 22 & 14 & 45 & $2.71(1.08 ; 6.79)$ & 0.033 & 29 & 16 & 18 & 39 & $7.00(2.65 ; 18.50)$ & 0.001 \\
\hline
\end{tabular}

Presence of great difficulty or incapacity in ADLsb/mobility

\begin{tabular}{|c|c|c|c|c|c|c|c|c|c|c|c|c|}
\hline No & 92 & 46 & 01 & 03 & 1 & & 86 & 47 & 09 & 20 & 1 & \\
\hline Yes & 107 & 54 & 30 & 97 & $25.79(3.45 ; 192.8)$ & 0.002 & 98 & 53 & 37 & 80 & $3.61(1.65 ; 7.90)$ & 0.001 \\
\hline
\end{tabular}

Use of health services

Seeking the same place when needing medical care

\begin{tabular}{|c|c|c|c|c|c|c|c|c|c|c|c|c|}
\hline Yes & 172 & 86 & 26 & 84 & 1 & & 170 & 92 & 43 & 93 & 1 & \\
\hline No & 27 & 14 & 05 & 16 & $1.23(0.43 ; 3.46)$ & 0.702 & 14 & 08 & 03 & 07 & $0.85(0.23 ; 3.08)$ & 0.801 \\
\hline \multicolumn{13}{|c|}{ edical consultation over last 12 months } \\
\hline Yes & 155 & 78 & 24 & 77 & 1 & & 152 & 83 & 43 & 93 & 1 & \\
\hline No & 43 & 22 & 07 & 23 & $1.05(0.42 ; 2.60)$ & 0.914 & 32 & 17 & 03 & 07 & $0.33(0.10 ; 1.13)$ & 0.079 \\
\hline \multicolumn{13}{|c|}{ ospitalization over last 12 months } \\
\hline No & 174 & 87 & 25 & 81 & 1 & & 160 & 87 & 34 & 74 & 1 & \\
\hline Yes & 25 & 13 & 06 & 19 & $1.67(0.62 ; 4.47)$ & 0.307 & 24 & 13 & 12 & 26 & $2.35(1.07 ; 5.16)$ & 0.033 \\
\hline \multicolumn{13}{|c|}{ ealth insurance plan coverage } \\
\hline Yes & 56 & 28 & 04 & 13 & 1 & & 40 & 22 & 10 & 22 & 1 & \\
\hline No & 143 & 72 & 27 & 87 & $2.64(0.88 ; 7.90)$ & 0.082 & 144 & 78 & 36 & 78 & $1.00(0.46 ; 2.19)$ & 1.000 \\
\hline
\end{tabular}

ADLs: activities of daily living.

${ }^{a}$ Chronic diseases investigated: spine or back diseases, arthritis or rheumatism, cancer, diabetes, bronchitis or asthma, hypertension, heart disease, chronic kidney disease, depression, tuberculosis and cirrhosis.

b Activities investigated: feeding oneself; having a bath/shower or going to the bathroom; running, lifting heavy objects, practicing sports or doing heavy work; pushing a table or doing domestic repairs; stooping, kneeling down or bending over; walking for more than one kilometer and walking around 100 meters. 
elderly individuals measured by the self-assessments and the assessments by the secondary informants continued to be present (Table 3).

In the final model based on self-rated health, the socioeconomic and demographic dimensions and health conditions remained statistically significant. The variables that influenced the elderly individuals' self-rated health and the secondary informants' assessment of the elderly individuals' health as poor were different. The number of chronic diseases presented by the elderly individuals was only relevant in the model based on secondary informants (Table 4).

Among the secondary informants who assessed their own health as poor, there was a greater chance that they would also assess the elderly individuals' health as poor $(\mathrm{OR}=2.68 ; 95 \% \mathrm{CI}: 1.04 ; 6.88)$, and remained associated independently of the other variables already included in the final model.

The assessment of the elderly subjects' health made by the secondary informants taking the elderly individuals' perspective resulted in a small change to the magnitude of the associations encountered, in comparison with the health assessment made by the secondary informants from their own perspective. Reports of two or three chronic diseases presented OR $=4.33$ (95\% CI: $1.65 ; 11.37)$; reports of four or more diseases presented $\mathrm{OR}=8.02(95 \% \mathrm{CI}: 2.71 ; 23.72)$; and the presence of great difficulty or incapacity in ADLs/ mobility presented OR $=2.60$ (95\% CI: 1.16;5.82). Furthermore, the variable of family income remained inversely associated with the health assessment: OR $=0.47(95 \%$ CI: $0.22 ; 1.00)$ for 1 to 3 salaries and OR $=0.26$ (95\% CI: $0.10 ; 0.67)$ for $\geq 3.1$ salaries $)$. When the secondary informants answered taking the elderly subjects' perspective, assessment of their own health as poor was not associated independently with the elderly individuals' health $(\mathrm{OR}=1.23$; 95\% CI: 0.46;3.30).

The Hosmer-Lemeshow test on the fit of the final model for the assessment on the elderly subjects' health by the secondary informants, from the elderly individuals' perspective, was $\mathrm{X}^{2}=11.37$, with $\mathrm{p}=0.50$. The results from determining the fit of the other two models are presented in Table 4.

Table 3. Factors that remained associated with assessment of the elderly subjects' health as poor, in multivariate analysis in each of the groups of variables analyzed: results based on information supplied by the elderly subjects and by the secondary informants. Belo Horizonte, Southeastern Brazil, 2007.

\begin{tabular}{|c|c|c|c|c|}
\hline \multirow[t]{2}{*}{ Variable } & \multicolumn{2}{|c|}{$\begin{array}{l}\text { Elderly subjects' self-assessed } \\
\text { health }\end{array}$} & \multicolumn{2}{|c|}{$\begin{array}{l}\text { Assessment of elderly subjects' health } \\
\text { made by secondary informants }\end{array}$} \\
\hline & OR $(95 \% \mathrm{Cl})$ & $\mathrm{p}$ & OR $(95 \% \mathrm{Cl})$ & $\mathrm{p}$ \\
\hline \multicolumn{5}{|c|}{ Socioeconomic and demographic variables ${ }^{\mathbf{a}}$} \\
\hline \multicolumn{5}{|l|}{ Age (years) } \\
\hline 60 to 64 & 1 & & - & \\
\hline 65 to 69 & $3.88(1.38 ; 10.94)$ & 0.010 & - & \\
\hline 70 or over & $1.95(0.70 ; 5.45)$ & 0.204 & - & \\
\hline \multicolumn{5}{|l|}{ Health conditions } \\
\hline \multicolumn{5}{|c|}{ Number of chronic diseases ${ }^{\mathbf{b}}$} \\
\hline Up to 1 & - & & 1 & \\
\hline 2 to 3 & - & & $2.52(0.99 ; 6.41)$ & 0.053 \\
\hline 4 or more & - & & $4.90(1.77 ; 13.58)$ & 0.002 \\
\hline \multicolumn{5}{|c|}{ Presence of great difficulty or incapacity in ADLs/mobility } \\
\hline No & 1 & & 1 & \\
\hline Yes & $25.79(3.45 ; 192.80)$ & 0.002 & $2.40(1.05 ; 5.51)$ & 0.039 \\
\hline \multicolumn{5}{|c|}{ Use of health services ${ }^{c}$} \\
\hline \multicolumn{5}{|c|}{ Hospitalization over the last 12 months } \\
\hline No & - & & 1 & \\
\hline Yes & - & & $2.35(1.07 ; 5.16)$ & 0.033 \\
\hline
\end{tabular}

ADLs: activities of daily living.

${ }^{a}$ Variable adjusted according to sex, marital status, color, monthly family income, schooling level and work during the preceding week.

b Chronic diseases investigated: spine or back diseases, arthritis or rheumatism, cancer, diabetes, bronchitis or asthma, hypertension, heart disease, chronic kidney disease, depression, tuberculosis and cirrhosis.

' Variables adjusted according to habit of seeking the same place when needing medical care, medical consultation over the last 12 months and coverage of the medical or dental health insurance plan. 
Table 4. Factors independently associated with assessment of elderly subjects' health as poor, in multiple analysis in the final model: results based on self-assessment and on information supplied by secondary informants. Belo Horizonte, Southeastern Brazil, 2007.

\begin{tabular}{|c|c|c|c|c|}
\hline \multirow[t]{2}{*}{ Variable } & \multicolumn{2}{|c|}{ Self-assessed health ${ }^{\mathbf{a}}$} & \multicolumn{2}{|c|}{$\begin{array}{l}\text { Health assessment made by } \\
\text { secondary informants }\end{array}$} \\
\hline & OR $(95 \% \mathrm{Cl})$ & $\mathrm{p}$ & OR $(95 \% \mathrm{Cl})$ & $\mathrm{p}$ \\
\hline \multicolumn{5}{|l|}{ Age (years) } \\
\hline 60 to 64 & 1 & & - & \\
\hline 65 to 69 & $3.74(1.25 ; 11.20)$ & 0.019 & - & \\
\hline 70 or over & $1.41(0.49 ; 4.09)$ & 0.529 & - & \\
\hline \multicolumn{5}{|c|}{ Number of chronic diseases } \\
\hline Up to 1 & - & & 1 & \\
\hline 2 to 3 & - & & $2.52(0.99 ; 6.41)$ & 0.056 \\
\hline 4 or more & - & & $4.90(1.77 ; 13.58)$ & 0.002 \\
\hline \multicolumn{5}{|c|}{ Presence of great difficulty or incapacity in ADLs/mobility } \\
\hline No & 1 & & 1 & \\
\hline Yes & $26.88(3.55 ; 203.51)$ & 0.001 & $2.40(1.05 ; 5.51)$ & 0.040 \\
\hline
\end{tabular}

ADLs: activities of daily living.

Chronic diseases investigated: spine or back diseases, arthritis or rheumatism, cancer, diabetes, bronchitis or asthma, hypertension, heart disease, chronic kidney disease, depression, tuberculosis and cirrhosis.

${ }^{a}$ Hosmer-Lemeshow test on final overall model for elderly subjects' self-assessed health: $X^{2}=3.36 ; p=0.19$.

${ }^{\mathbf{b}}$ Hosmer-Lemeshow test on final overall model for health assessment by secondary informants from their own perspective: $X^{2}=$ $3.63 ; p=0.16 ;$ and $X^{2}=11.02 ; p=0.14$, for the model including secondary informants' own self-assessed health.

\section{DISCUSSION}

The results show that there were important differences between the model for assessment of the elderly individuals' health based on their own responses and the model based on the responses of the secondary informants. The findings suggest that the elderly subjects tend to place value on their limitations or incapacity to perform ADLs/mobility, while the secondary informants tend to replicate a biomedical model that place value on diagnoses of chronic diseases more than on the consequences of these diseases for the elderly subjects' quality of life. Moreover, the results indicate that the secondary informants with worse self-rated health present almost three times greater chance of reporting the elderly subjects' health in the same manner.

The associations between explanatory variables and health assessment provided by the elderly individual and by the proxy have the same direction. A study on the influence of substitute respondents on the perceptions of the health of elderly participants in PNAD 1998 and 2003 and members of the Bambuí cohort, in Minas Gerais, Brazil (2007), ${ }^{8}$ found similar results. However, this finding should not be taken to be evidence for absence of bias, since comparison between the explanatory models tested did not show any association between the number of chronic diseases and self-assessment of the elderly subjects' health as poor. This factor presented a direct correlation when the health assessment was made by the secondary informants.
According to the elderly subjects, being between 65 and 69 years and having great difficulty or incapacity in at least one ADL were associated with assessment of health as poor. A Canadian study that compared 9,371 individuals aged 55-64 and 65-74 years ${ }^{13}$ did not observe worse assessments of health in the older age group, probably because of the survival effect and the lower life expectancy at more advanced ages. According to the survival effect, individuals who are more ill already have died or become institutionalized, and therefore the surviving cohort living in their own homes will be less ill and more healthy. ${ }^{13}$ It is also possible that individuals modify the way in which they assess their health with advancing age, or use different age group references when doing so.

In the present study, monthly family income, sex and schooling level were not associated with assessed poor health among the elderly individuals. Regarding sex, the absence of association had already been noted in other study. ${ }^{7}$ The lack of associations with income and schooling levels, also reported in other studies, ${ }^{3,4}$ may be explained by the great homogeneity of the participants in these respects. All the participants live in a low-income district and have little or no schooling.

In the model based on assessments by secondary informants, the association with the number of chronic diseases stood out, along with the fact that their magnitude was greater than the magnitude of limitations on functional capacity. 
In addition to the secondary informants' greater valuation of the diagnosis than of the impact of the disease, some studies have indicated that secondary informants tend to place value on the presence of deficiencies and functional incapacities in the manner that differs from that of the individuals affected. A study conducted in the United Kingdom in 1994 and 1995, based on the National Health Interview Survey on Disability, with 145,007 participants aged 18 years or over, concluded that the evaluations made by secondary informants underestimated the frequency of disability in individuals aged from 18 to 64 years, while the inverse occurred for individuals aged 65 years onwards. ${ }^{15} \mathrm{~A}$ study that assessed the functional capacity of 287,540 individuals aged 14 years or over, using data from PNAD 2003, found that the prevalence of limitations on activities among the elderly individuals was systematically higher when the responses were provided by secondary informants. ${ }^{2}$ Further studies are required in order to gain a better understanding of the influence of secondary informants on the perceptions of elderly individuals' functional capacity, since there may be differences in the perceptions of activities that are considered relevant for health assessments by the individuals themselves and by secondary informants.

It is important to emphasize that the variable used for assessing functional capacity (prevalence of great difficulty or incapacity in ADLs/mobility) did not discriminate between the different levels of limitation faced by the elderly individuals, or between the types of activity affected. On the other hand, this variable made it possible to identify the elderly individuals with lower autonomy.

The model for assessing elderly individuals' health based on the responses of secondary informants was slightly influenced by the secondary informants' perspective on the elderly subjects' health. A study that analyzed both of the secondary informants' response perspectives among 272 elderly individuals found greater concordance between the elderly individuals and secondary informants when the latter were taking the elderly subjects' perspective in providing responses to a quality-of-life instrument relating to elderly individuals' health. ${ }^{9}$ In this respect, greater similarity between the model based on the elderly individuals' responses and the model based on the secondary informants' responses would be expected when the secondary informants were speaking from the elderly individuals' perspective. However, this was not found in the present study.

One possible explanation for the differences observed between self-reporting and reports from secondary informants is the difference in age, given that $88 \%$ of the secondary informants were under the age of 60 years. It is likely that younger individuals would take different viewpoints in assessing health. It has been recognized that self-assessed health declines with age, and that older adults are more likely to refer to their health as poor than are younger adults. ${ }^{3,4}$ A study conducted in Canada compared predictors for selfassessed health between younger adults (25-54 years) and older adults ( 55 years or over) and concluded that the younger adults used a wider variety of factors and criteria for assessing their own health. ${ }^{13}$

The present study showed internal validity, since it not have any systematic errors in measurements on the variables investigated. Nevertheless, generalization of the data to other populations should be done cautiously.

One limitation of the present study relates to the small number of participants, especially in some of the categories analyzed. Another limitation is the homogeneity of the population, which meant that it was not possible to discriminate between certain characteristics associated with self-assessed health, such as income and schooling level. Among the 230 participants, the study had a power of $97 \%$ for detecting a prevalence ratio greater than or equal to 3.00 , with $\mathrm{p}<0.05$, taking the prevalence of exposure to be $50 \%$ and the prevalence of event of interest to be $20 \%$ and $30 \%$ among exposed and unexposed individuals, respectively.

The focus of the present study is not on adding new issues to the comprehension of factors influencing self-assessment of elderly individuals' health. Rather, its aims to compare explanatory models based on selfreporting and reports from secondary informants, using objective explanatory variables with lower potential observer bias that have been recognized as relevant for health assessment. Thus, the emphasis in this investigation is on differentiating the associations found in models based on self-reporting and models based on reports from secondary informants.

In conclusion, the differences observed between self-reporting and reports from secondary informants confirmed that secondary reporting is subjective and individual in nature and brought out concerns regarding the use of secondary informants for measuring assessments of elderly people's health. It is recommended that such assessments should be made by the elderly individuals themselves. In cases in which other people have to make the assessment, it is important to take into consideration the secondary informants' own health conditions and the perspective used. 


\section{REFERENCES}

1. Barros MBA, Cesar CLG, Carandina L, Torre GD. Desigualdades sociais na prevalência de doenças crônicas no Brasil, PNAD-2003. Cienc Saude Coletiva. 2006;11(4):911-26. DOI:10.1590/S141381232006000400014

2. Costa AJL. Metodologias e indicadores para avaliação da capacidade funcional: análise preliminar do Suplemento Saúde da Pesquisa Nacional por Amostra de Domicílios - PNAD, Brasil, 2003 Cienc Saude Coletiva. 2006;11(4):927-40. DOI:10.1590/S141381232006000400015

3. Dachs JNW. Determinantes das desigualdades na auto-avaliação do estado de saúde no Brasil: análise dos dados da PNAD/1998. Cienc Saude Coletiva. 2002;7(4):641-57. DOI:10.1590/S141381232002000400004

4. Dachs JNW, Santos APR. Auto-avaliação do estado de saúde no Brasil: análise dos dados da PNAD/2003. Cienc Saude Coletiva. 2006;11(4):887-94. DOI:10.1590/S1413-81232006000400012

5. Hyland A, Cummings KM, Lynn WR, Corle D, Giffen CA. Effect of proxy-reported smoking status on population estimates of smoking prevalence. Am J Epidemiol.1997;145(8):746-51.

6. Idler EL, Benyamini Y. Self-rated health and mortality: a review of twenty-seven community studies. I Health Soc Behav.1997;38(1):21-37. DOI:10.2307/2955359

7. Lima-Costa MF, Firmo JOA, Uchôa E. A estrutura da auto-avaliação da saúde entre idosos: projeto Bambuí. Rev Saude Publica. 2004;38(6):827-34. DOI:10.1590/ S0034-89102004000600011

8. Lima-Costa MF, Peixoto SV, Matos DL, Firmo JOA, Uchôa E. A influência de respondente substituto na percepção da saúde de idosos: um estudo baseado na Pesquisa Nacional por Amostra de Domicílios (1998, 2003) e na coorte de Bambuí, Minas Gerais, Brasil. Cad Saude Publica. 2007;23(8):1893-902. DOI:10.1590/S0102-311X2007000800016

9. Mcphail S, Beller E, Haines M, Haines T. Two perspectives of proxy reporting of health-related quality of life using the Euroqol-5D, an investigation of agreement. Medical Care. 2008;46(11):1140-8. DOI:10.1097/MLR.0b013e31817d69a6
10. Nelson LM, Longstreth Jr WT, Koepsell TT, Van Belle G. Proxy respondents in epidemiologic research. Epidemiol Reviews. 1990;12:71-86.

11. Santos SM, Chor D, Werneck GL, Coutinho ESF. Associação entre fatores contextuais e auto-avaliação de saúde: uma revisão sistemática de estudos multinível. Cad Saude Publica. 2007;23(11):2533-54. DOI:10.1590/S0102-311X2007001100002

12. Shields M. Proxy reporting in the National Population Health Survey. Health Reports. 2000;12(1):21-39.

13. Shooshtari S, Menec V, Tate R. Comparing predictors of positive and negative self-rated health between younger (25-54) and older (55+) canadian adults: a longitudinal study of well-being. Res Aging. 2007;29(6):512-54. DOI:10.1177/0164027507305729

14. Tavares DMS, Guiderri GCB, Saúde MIBM. Características sócio-demográficas, condições de saúde e utilização de serviços de saúde por idosos. Rev Eletronica Enferm. 2008;10(2):299-309.

15. Todorov A, Kirchner C. Bias in proxies' reports of disability: data from the National Health Interview Survey on Disability. Am J Pub Health. 2000;90(8):1248-53. DOI:10.2105/AJPH.90.8.1248

16. Uchôa E. Contribuição da antropologia para uma abordagem das questões relativas à saúde do idoso. Cad Saude Publica. 2003;19(3):849-53. DOI:10.1590/ S0102-311X2003000300017

17. Viacava F, Dachs $N$, Travassos C. Os inquéritos domiciliares e o Sistema Nacional de Informações em Saúde. Cienc Saude Coletiva. 2006;11(4):863-9. DOI:10.1590/S1413-81232006000400002

18. Yunhwan L. The predictive value of self assessed general, physical, and mental health on functional decline and mortality in older adults. J Epidemiol Community Health. 2000;54:123-9. DOI:10.1136/ jech.54.2.123

19. Jardim R, Barreto SM, Giatti L. Confiabilidade das informações obtidas de informante secundário em inquéritos de saúde. Cad Saude Publica. 2010; no prelo.

20. Jardim R, Barreto SM, Gonçalves LG. Confiabilidade do informante secundário em inquéritos de saúde. $R$ Bras Est Pop. 2009;36(1):141-4.

Study funded by Fundação de Amparo à Pesquisa do Estado de Minas Gerais (Process n 13218) and Fundação Nacional de Saúde (Process $\left.n^{\circ} .661 / 20\right)$.

SM Barreto was supported by Conselho Nacional de Desenvolvimento Científi co e Tecnológico (CNPq - Process $n^{\circ} 13218$ and $\mathrm{n}^{\circ}$ 3661/20; productivity bursary)

Article base on the doctoral thesis of R Jardim, presented to the Universidade Federal de Minas Gerais in 2009.

The authors declare that there are no conflicts of interest. 